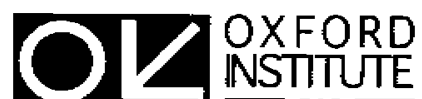 \\ NSTITUTE

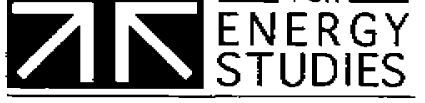

\section{Environmental Regulation by Private Contest}

\author{
Anthony G. Heyes
}

Oxford Institute for Energy Studies

EV20

1995 


\title{
ENVIRONMENTAL REGULATION \\ BY \\ PRIVATE CONTEST
}

\author{
Anthony G. Heyes
}

\begin{abstract}
It is widely expected that the recent trend (in the USA, EU and elsewhere) towards an increased role for private agents and agencies in the formulation and enforcement of environmental regulation will continue. If environmental regulation is to be "privatized" in this way it is natural to ask how far the activities of environmental groups, on whose shoulders much of the responsibility for defending the environment is likely to fall, should be subsidized or taxed. In this paper we identify the trade-offs involved and characterize the optimal subsidy/tax. The analysis is argued to have significant implications for how governments should think about the way in which fiscal law treats environmental NGOs.
\end{abstract}

EV20

Oxford Institute for Energy Studies

June 1995 
The contents of this paper are the author's sole responsibility. They do not necessarily represent the views of the Oxford Institute for Energy Studies or any of its Members

\section{Copyright $^{\mathbb{C}} 1995$}

\section{Oxford Institute for Energy Studies}

All rights reserved. No part of this publication may be reproduced, stored in a retrieval system, or transmitted in any form or by any means, electronic, mechanical, photocopying, recording, or otherwise, without prior permission of the Oxford Institute for Energy Studies.

This publication is sold subject to the condition that it shall not, by way of trade or otherwise, be lent, resold, hired out, or otherwise circulated without the publisher's prior consent in any form of binding or cover other than that in which it is published and without a similar condition including this condition being imposed on the subsequent purchaser.

\section{ISBN $094806188 \mathrm{X}$}


Anthony G. Heyes is a Research Fellow at the Oxford Institute for Energy Studies, and concurrently a Fellow of Nuffield College. He has an MA from the University of Cambridge and a Ph.D. from McGill University, Montreal. His research interests are in the regulation of the environmental impacts of energy production, transportation and usage. 


\section{CONTENTS}

INTRODUCTION

1 MODEL 4

2 WELFARE AND THE OPTIMAL RATE OF TAX 10

$\begin{array}{lll}3 & \text { CONCLUSIONS } & 17\end{array}$

$\begin{array}{ll}\text { APPENDICES } & 23\end{array}$

FIGURES

BIBLIOGRAPHY 


\section{INTRODUCTION}

A trend has emerged, in recent years, towards putting an increased onus for the formulation and implementation of environmental regulation into private hands. In the USA Naysnerski and Tietenberg (1992), Miller (1988) and others have noted that the US Environmental Protection Agency (EPA) increasingly relies upon (and encourages) private litigants to bring suit against polluters. In the case of the US Clean Water Act in particular, private litigation now constitutes a major component of the overall enforcement effort. In its 1993 Green Paper EC93(47) the European Commission clearly signalled its intent to 'beef-up' the rights of individuals and environmental groups to pursue polluters for compensation for environmental damage done and to force the restoration of damaged sites. In so doing it was following a trend already set by the 1980 Comprehensive Environmental Response, Compensation and Liability Act (the so-called 'Superfund Act') in the USA and by more recent legislative reform in the Netherlands, Germany and elsewhere (see Probst et al (1995) or Probst and Portney (1992) for good expositions of the American case). Private action can also be preemptive, with legal injunctions being sort to prevent environmental damage from occurring in the first place by proscribing certain activities or by obliging firms to implement additional pollution control measures (Wilkinson (1993)). Proactive litigation of this type is increasingly popular (see Yaeger (1991), Heyes (1994)).

In addition to the civil courts there are a variety of other fora in which polluters and environmental groups 'contest' regulatory decisions. Many planning decisions, for example, involve prior public consultation such that both sides have a formal avenue for input into the regulatory process at the licensing (or licence renewal) stage. Many regulatory decisions are subject to judicial review or assessment by administrative tribunal. In addition, both sides can make efforts to lobby or capture regulators and politicians directly, or to apply popular pressure through media-lobbying or 'direct action' (Boehmer-Christiansen (1990)) ${ }^{2}$. Such activity may be able to impact upon de jure regulatory stipulations directly or, more likely, impact upon the stringency of de facto or effective regulation by influencing the funding of enforcement.

Naysnerski and Tietenberg (1992) are not alone in calling for an extension of the role of private contests, in one guise or another, in the determination of environmental controls and Baik and Shogren (1994) contend that 'society is considering extending the reaches of this class of contest'. Lawmakers in Canada, to take another example, are committed to empowering private agents and agencies 'in virtually every aspect of the pollution control process, from the drafting 
of regulations to the formulation of individual licenses and the taking of enforcement actions' (Law Reform Commission of Canada (1988: 59)). Such an extension is popularly seen as a move towards a 'free market' solution to growing environmental problems and, in the current political climate, many regard a trend in this direction as an inevitable part of the modernization of environmental regulation (Heyes (1994, 1995), Yaeger (1991)).

If the process of environmental regulation is to be 'privatized' in this way it is natural to ask whether it would be desirable for the state to subsidize (or tax) the activities of those environmental groups on whose shoulders much of the responsibility for defending the environment is to be placed and, if so, to what extent. This is the question addressed in this paper.

Shavell (1982) argues that the private incentive to bring environmental suits is likely to be inadequate because of the public nature of the rewards in many cases, and that this could provide a rationale for subsidizing such action. This public good aspect of the problem features in our analysis but is not the focus of it. We develop a simple model in which private environmental groups and firms contest regulatory decisions. Those decisions could be about whether or not to introduce a particular regulation, or - in contexts in which courts and enforcement agencies retain significant discretion in implementation - whether or not to enforce a particular requirement in a given case. It is assumed that the environmental benefit from any regulatory action is common knowledge, but that the firm has private information regarding compliance costs.

Baik and Shogren (1994) adopt a contest model of the sort we will use here to look at how legal costs should be shared in environmental civil law cases. Whilst their insights are very useful their analytic framework is inadequate in a number of ways. Principal amongst these is their assumption that interested parties compete to win a reward of fixed, commonly known size (i.e the cost of regulatory compliance exactly equals the value of the environmental benefits generated and both are common knowledge). This assumes away the really interesting aspects of environmental policy-making - those involving the trading-off of (often uncertain) costs and benefits. Social loss, in their analysis, is simply the total effort expended by the two sides in the conflict. The problem with such a framework for studying regulatory contests (and, most especially, for making any normative asessment of them) is that there is no coherent reason for 
the contests to exist at all. The planner could always increase welfare simply by imposing a decision - any decision - since welfare is invariant to the direction of that decision. ${ }^{3}$

In the model presented in this paper contests perform a 'sorting' role. Because firms have private information about the cost implications of different regulatory actions they can contest different cases with different degrees of vigour - in particular they can focus their efforts on winning those cases where the compliance cost implications of their losing would be comparatively large. Here, because the firm has private information which it 'reveals' during the contest, the welfare loss under contests can be less than what it would be if the planner were to impose outcomes as best he could given the information available to him. Thus the existence of a contest system can be justified as a second-best means of making sure that firms tend to win regulatory relief when compliance costs are high vis-a-vis the value of the environmental damage averted, but not when they are low.

The paper addresses a highly topical policy issue: the role of NGOs in the formulation, implementation and enforcement of environmental policy. The economics of regulation literature now includes a long list of papers on the behaviour of regulated firms and regulatory agencies, but not on NGOs whose advocacy (in civil law courts and a variety of other fora) plays an increasingly important role in regulation. There exists a more general literature on rent-seeking and contests which includes Hillman and Riley (1989), Buchanan et al (1990), Cairns (1992) and many of the citations there-in. The related literature on the design and enforcement of regulations when the firm has private information regarding compliance costs includes Baron and Myerson (1982) and Xepedeas (1991)

O.I.E.S 


\section{MODEL}

A firm and a private agent (which may be an individual, some coalition of individuals or an environmental group (EG)) contest a regulatory decision. This may, for example, be the decision regarding whether or not to oblige the firm to fit a particular piece of equipment, or to allow it to locate a particular plant at a particular site. Alternatively it may be regarding whether or not to force a firm to clean up a contaminated or otherwise damaged site. The benefit to the EG of winning is some fraction $(l-m)$ of the total monetary value of the environmental damage which the regulation would proscribe, $d$ (the parameter $m$ will capture the degree to which the rewards from EG effort are public and so will proxy the strength of the underincentive effect identified by Shavell $(1982)^{4}$ ). In that event the cost to the firms of complying with the decision is $c$, which takes the value $c_{h}$ ('high') with probability $a$ and $c_{l}$ ('low') with the complementary probability ( $I$ a). The game is one of asymmetric, incomplete information: the firm observes c privately at the start of the game, the distribution from which it is drawn (i.e., the true value of $a$ ) being common knowledge. For sake of interest it will be assumed that $c_{h}>d>c_{l}>0.5$

The EG and firm choose how much effort to expend in a particular regulatory contest. These will be denoted $x$ and $y$ respectively and constitute the real resource cost of the rent-seeking efforts of the two parties. The government may place an ad valorem subsidy, at a rate $s$, on the activities of the environmental group (a negative $s$ corresponds to the special case of a tax). The aim of our analysis is to investigate the positive and normative impacts of such tax-cum-subsidy.

The contest itself is modelled as a 'lottery auction' whereby the probability of winning, $p(x, y)$, is determined by a unit-logit function:

$[1] p(x, y)=\frac{x}{x+y}$

In effect the two parties 'bid' to win the regulatory decision, where the bid takes the form of expending effort in the contest. This is a popular approach and there are various reasons why it is a 'natural' one to choose in this context (see Hirshleifer (1988) and Dixit (1987) for examples and discussion. Hirshleifer also looks at the comparative merits of alternative specifications of the 
winning function). Notice that, for positive $y, p(x, y)$ approaches unity as $x$ is increased without bound, but that $p(x, y)=1$ if and only if $y=0$. Thus the EG (firm) increases its chance of winning (ceteris paribus) by increasing its effort input, but only wins with certainty when the result is uncontested. The lottery or imperfectly discriminating auction is used extensively in modelling 'noisy' decision environments in which the higher bidder - or that party which exerts the greatest effort in some other sense - is more likely to be successful, but is not necessarily so. ${ }^{6}$

It is also natural to suppose that the EG moves first and the firm follows. Under civil and criminal law the moving party states its case first, the defendant (in this case the polluting firm) then chooses whether and how vigorously to defend itself. The same sequence is adopted in the procedural codes of most administrative review bodies and regulatory tribunals (see, for examples, Hawkins and Thomas (1988), Boehmer-Christiansen (1990)). Although the 'rules of the game' (including the ordering of moves) are likely to be much less clear cut in the event that the contest takes place through media or political lobbying the assumption that the EG moves first still makes sense. The EG initially chooses how much campaigning effort to put into a particular case (e.g., how many leaflets to distribute, how many names to collect on a petition before presenting it to the appropriate politician). Once the case is exposed in the political or public arena through the work of the EG, the firm has the option of countering it through the disemination of propaganda of its own or through the offer of 'bribes' to third parties. 7,8

As always in a Stackelberg game, we solve backwards. Knowing $c$, and having observed $x$, the firm's problem is to minimize the sum of expected compliance costs and own contest effort ${ }^{9}$

$[2] \operatorname{Min}_{y 20}\left\{p(x, y) \cdot c_{i}+y\right\}$

Solving this problem yields the firm's reaction function $-y\left(x ; c_{j}\right)$ :

[3] $y\left(x \mid c_{i}\right)=\left\{\begin{array}{rl}\sqrt{c_{i} x}-x & 0<x<c_{i} \\ 0 & c_{i}<x\end{array}\right.$ 
simple manipulation of which implies the following (which is stated without proof):

Proposition [1]: For any particular $c_{i}$ the firm's reaction function is non-monotonic in $x$. More concretely, $y_{x}\left(x \mid c_{j}\right)>0$ iff $0<x<\left(c_{i} / 4\right)$. Also $y\left(x \mid c_{i}\right)=0$ for $x>c_{i}$ and $y\left(x \mid c_{h}\right)>y\left(x \mid c_{j}\right)$ for all $x<c_{h}$.

The representative firm has, then, two reaction functions - one for each value of $c$ - and these are characterized in Figure [1] ${ }^{10}$ The non-monotonicity of $y\left(x \mid c_{j}\right)$ is of some interest. For comparatively low levels of contest effort by the environmental group, the firm responds to increases in that level by increasing its own 'defensive' efforts. Beyond some point, however, the firm reacts to further increases contrarily. It is a characteristic of lottery auctions that the crossderivative $d^{2}(1-p(x, y)) / d x . d y$ is positive - implying, in this case, that increases in $x$ serve to increase the marginal product of increase in $y$ - when and only when $x$ is sufficiently small (see Hirshleifer (1988)), and it is this which drives the non-monotonicity.

The last part of the proposition says that for any given level of effort by its opponent the firm 'fights its corner' more vigorously when the costs of compliance would be high than when they would be low, which accords with intuition. ${ }^{11}$

The environmental group chooses $x$ to minimize contest expenditures plus $(l-m)$ times expected environmental damage. The environmental group may 'care' because it represents those who stand to bear some or all of the burden of any such damage (e.g. an angling club opposing dumping in a river, or a residents association opposing a new power station) or for altruistic reasons. Analytically all that matters is that the EG acts 'as if the proportion $(l-m)$ of any environmental damage were to be incident upon it. As Stackelberg leader its problem is:

[4] $\operatorname{Min}_{x \geq 0}\left\{\left[a \cdot\left(1-p\left(x, y\left(x \mid c_{h}\right)\right)+(1-a) \cdot\left(1-p\left(x, y\left(x \mid c_{\nu}\right)\right)\right] \cdot(1-m) \cdot d+(1-s) \cdot x\right\}\right.\right.$

At the moment it makes its decision regarding how much contest effort to commit to fighting a particular case, the EG does not know the compliance cost implications of the 
regulatory decision it is calling for. It is, however, able to anticipate how robustly the firm will oppose those efforts contingent upon its private information regarding those costs. With probability $a$ the realized value of $c$ will be $c_{k_{2}}$ and the firm will choose $y=y\left(x \mid c_{k}\right)$ such that the chance of its winning the contest (i.e. the chance of the EG losing) is $\left(I-p\left(x, y\left(x \mid c_{k}\right)\right)\right)$. With probability $(I-a)$, on the other hand, $c=c_{l}$ and the EG loses with some (smaller) probability ( $I$ $p\left(x, y\left(x \mid c_{y}\right)\right)$ ). In either event the cost to the EG of losing is $(I-m) . d$. The final term in Equation [4] is simply the EG's contest expenditures (net of any tax-cum-subsidy on its activities) - (l-s).x. Increasing the intensity with which it contests a given decision is costly to the EG but increases the chance of that decision being in its favour.

The solution to the environmental group's problem is implicitly defined by the associated first-order condition (an asterisk denotes a solution value)

$[5](1-s)=d \cdot(1-m) \cdot\left[a \cdot \frac{d p\left(x^{*}, y\left(x^{*} \mid c_{k}\right)\right)}{d x}+(1-a) \cdot \frac{d p\left(x^{*}, y\left(x^{*} \mid c_{\nu}\right)\right)}{d x}\right]$

where the impact of a marginal increase in the EG's contest efforts upon its probability in equilibrium of winning a representative contest is described by:

[6] $\frac{d p\left(x, y\left(x \mid c_{i}\right)\right)}{d x}=\frac{\delta p}{\delta x}+\frac{\delta p}{\delta y} \cdot \frac{\delta y}{\delta x}=\left\{\begin{array}{cl}1 / \sqrt{4 \cdot c_{i} x} & 0<x<c_{i} \\ 0 & c_{i}<x\end{array}\right.$

The left-hand side of Equation [5] is the (net) marginal cost to the EG of increasing $x$. The right-hand side is the marginal benefit derived by it from so doing and is the product of the marginal increase induced in the equilibrium probability of a win (the composite term in square brackets) and its benefit from such a favourable decision, $(I-m) . d$. Equation [6] highlights the fact that the equilibrium impact of an incremental increase in $x$ upon $p$ has two components: the direct impact is unambiguously positive whilst the indirect or strategic impact - that following from

O.I.E.S. 
induced adjustments in $y$ - is ambiguous. This latter ambiguity follows from the non-monotonicity of the firm's reaction function: from the point of view of the firm $y$ and $x$ are strategic complements when and only when $x<(c / 4)$, they are strategic substitutes elsewhere. Private optimality requires that $x$ be increased up to $x^{*}$ - the point at which the two sides are brought into equation - which is implicitly defined by Equation [5]. Restricting attention for the rest of our analysis to equilibria characterized by interior solutions Equation [5] becomes:

$[7](1-s)=d \cdot(1-m) \cdot\left[\frac{a}{2 \cdot \sqrt{c_{h} x^{*}}}+\frac{(1-a)}{2 \cdot \sqrt{c_{h} x^{*}}}\right]$,

which can be rearranged to yield an explicit expression for $x^{*}$ as a function of the rate of subsidy:

$[8] x^{\prime}(s)=\left[\frac{d .(1-m)}{2 .(1-s)} \cdot\left(\frac{a}{\sqrt{c_{h}}}+\frac{(1-a)}{\sqrt{c_{l}}}\right)\right]^{2}$

For a particular value of $s$, then, Equation [8] defines the level of contest effort that the environmental group will exert in a representative contest. The polluter (or would-be polluter) responds to this 'bid' by exerting contest effort of its own - equal to either $\left[\sqrt{c_{h} \cdot x(s)}-x(s)\right]$ or $\left[\sqrt{c_{t} x(s)}-x(s)\right]$, depending upon its private information regarding the compliance-cost implications of an adverse regulatory decision - such that the pair of state-contingent Stackelberg equilibria $\left\{x(s), y\left(x(s) \mid c_{h}\right)\right\}$ and $\left\{x(s), y\left(x(s) \mid c_{l}\right)\right\}$ are generated. Notice that the symmetry of the winning function (Equation [1]) implies that the EG (firm) is 'favourite' to win the contest in any given case if and only if $x>y(x<y)$. In Figure [2], for example, as things are drawn the environmental group is favourite to win when and only when $c=c_{r}{ }^{12}$

In preparation for the policy analysis in Section 2 it is useful to characterize the comparative static impact of changes in the policy instrument, the rate of tax-cum-subsidy, upon the equilibrium behaviours of the contestees and the outcomes of contests: 
Proposition [2]: A marginal increase in $s$ induces, in equilibrium, an increase in the intensity with which the environmental group contests all regulatory decisions. It induces an increase in the effort exerted by the firm in and only in those contests in which it (the firm) is already favourite. In any event the environmental group's likelihood of winning the contest is increased.

Proof: Appendix [1].

This is illustrated in Figure [3]. The increase in $s$ induces a rightward shift in $x(s) . y$ increases in and only in that case in which the equilibrium lies on the upward-sloping portion of the firm's state-contingent reaction function (i.e. where $y$ and $x$ are (local) strategic complements). As we have drawn it the Stackelberg equilibrium contingent on $c$ equalling $c_{h}$ moves from $A$ to $\mathrm{B}$, that contingent on $c$ equalling $c_{i}$ from $\mathrm{C}$ to $\mathrm{D}$. The last part of Proposition [2], that the overall impact of an increase in $s$ is to increase (in equilibrium) the probability that the EG will win - even in those cases in which both sides are induced to increase the intensity with which they contest the decision - is at the heart of the policy dilemma analysed in Section 2: manipulating $s$ to increase the chance that the environmental group wins when it is efficient that it should do so (i.e., when $c_{i}<d$ ) cannot be done without at the same time increasing the chances that it wins when it is not (i.e., on those occasions that $d<c_{i}$ ). 


\section{WELFARE AND THE OPTIMAL RATE OF TAX/SUBSIDY}

If enforcement is to be 'privatized' it is natural to ask how far (if at all) the activities of environmental groups such as the Environmental Defense Fund in the USA or Friends of the Earth in the UK - to whom part of the responsibility for making sure a contest-based regulatory system 'works' is being delegated - should be subsidized from the public purse. The value of subsidies in this context is that it allows the policymaker to 'tilt the playing field' on which the contests are to be fought and, in so doing, to manipulate the behaviours of the contestees and the probabilities of alternative outcomes. The dilemma implied by Proposition [2] is that this tilting cannot be done discriminately - making the environmental group more likely to win one contest implies making it more likely to win them all. (The underlying second-bestness - that arising from the firm's private information regarding the true value of $c$ in any given case - proscribes a more selective application of subsidies).

Defining a social loss function to comprise the sum of environmental damage, industry compliance costs and total contest efforts (the social cost of the latter depending in the usual way on the shadow cost of public funds). First-best would require $x=y=0$ and that the environmental group won when and only when $c=c_{l}$ (recall our assumption that $c_{h}>d>c_{p}>0$ ) - i.e, when and only when regulatory implementation would be cost efficient. This would imply an expected social loss equal to $\left(a \cdot d+(I-a) \cdot c_{\nu}\right)$. For convenience we use this first-best outcome as a reference point and can constuct a social loss function in terms of deviations from it:

[9] $S L=$

$$
a . p(s \mid h) \cdot\left(c_{h}-d\right)+(1-a) .(1-p(s \mid l)) \cdot\left(d-c_{l}\right)
$$

$$
+\left[a \cdot y\left(x(s) \mid c_{h}\right)+(1-a) \cdot y\left(x(s) \mid c_{l}\right)\right]+(1+\lambda \cdot s) \cdot x(s)
$$

(the notation has been simplified by adopting the convention that $p(s ; i)=p\left(x(s), y\left(x(s) \mid \mathcal{C}_{i}\right)\right.$ the equilibrium probability of the EG winning the contest if $c=c_{i}$ ). The parameter $\lambda$ is the shadow cost of public funds and is strictly positive. ${ }^{\mathrm{t3}}$

The components of the social loss function capture (respectively): (i) With probability 
$a . p(s \mid h)$ compliance costs will be high but the firm will lose the contest implying a loss vis-a-vis first-best of $\left(c_{h}-d\right)$. (ii) With probability $(I-a) \cdot(I-p(s \mid l))$ compliance costs will be low but the firm will win the contest, implying a loss of $\left(d-c_{l}\right)$. (iii) In all events both parties expend effort on the contest. The remaining terms capture the expected social cost of the aggregate effort expended in the course of the contest process itself.

By choosing $s$ the planner determines the pair of probabilities $p(s \mid h)$ and $p(s \mid l)$. Optimality will require that $s$ be chosen to minimize $S L$. The interior solution to the planner's problem, $s^{*}$, will be (implicitly) defined by the associated first-order condition:

[10]

$$
a \cdot p_{s}\left(s^{n} \mid h\right) \cdot\left(c_{h}-d\right)-(1-a) \cdot p_{s}\left(s^{n} \mid l\right) \cdot\left(d-c_{p}\right)
$$

$$
+\left[a \cdot y_{x}\left(x\left(s^{2}\right) \mid c_{h}\right) \cdot x_{s}\left(s^{*}\right)+(1-a) \cdot y_{x}\left(x\left(s^{*}\right) \mid c_{\nu}\right) \cdot x_{s}\left(s^{n}\right)\right]+\left[\lambda \cdot x\left(s^{*}\right)+\left(1+\lambda \cdot s^{*}\right) \cdot x_{s}\left(s^{*}\right)\right]=0
$$

The first line can be thought of as measuring the impact of any change in $s$ upon the 'quality' of the regulatory decision-making (i.e. the expected social burden of 'wrong' decisions), the second line the impact upon the real resource burden of the decision-making apparatus itself (what could loosely be called the 'transactions costs'). Notice that the final square bracket - the social cost of the EG's rent-seeking activities - has two terms, both of which are positive. Not only is the EG induced to increase the intensity with which it contests each decision but a greater share of its expenditures is now paid for out of public funds which command a welfare premium.

It is worth noting that it is relatively straightforward to show that the terms in the lower line are, in aggregate, positive, implying that the upper line is negative in the vicinity of equilibrium. This implies that optimality requires that $s$ be set at a level below that at which it would be set if the sole objective was to maximize the expected 'quality' of regulatory decisionmaking. ${ }^{14}$ Thus, whilst raising $s$ incrementally above $s^{*}$ necessarily improves the quality of regulation the benefit derived from that improvement does not warrant the additional transactions costs pursuant to it. The desire to avoid transactions costs - to maintain a lean apparatus for the resolution of regulatory conflict - may be a real motive for implementing apparently sub-optimal regulatory regimes in a number of contexts. Under the US Superfund Act, for instance, Probst

O.I.E.S. 
et al (1995) estimate that for every dollar spent on environmental enhancement the transaction cost burden is between 10 and 30 cents. This has lead the USEPA to consider techniques for 'fasttracking' decision-making in some cases even though it is understood that so doing increases the chance that a 'wrong' decision will be made.

Optimality requires that the various welfare impacts be traded off appropriately. The procedure amounts to one of trading off type 1 and type 2 errors: increasing $s$ means that the firm will be less likely to avoid regulations which are cost effective, but at the same time makes it more likely that it will be obliged to comply with others that are not. Both regulating when you shouldn't, and failing to regulate when you should, impose welfare penalties vis-a-vis first-best. Equation [9] highlights analytically the knife-edge on which the planner sits: setting the rate of subsidy too low will mean that polluters 'get away with' too much, setting it too high will mean that the playing field will be tilted too far against the firm and the stringency of environmental regulation - as determined by contests between the respective parties - will become excessive.

Proposition [3]: $\mathrm{s}^{*}$ may be positive or negative. Ceteris paribus, it is more likely to be positive when $a, p_{s}(0 \mid h)$ and/or $\left(c_{h}-d\right)$ are small, when $p_{s}(0 \mid l)$ and/or $\left(d-c_{j}\right)$ are large.

Proof: This can be seen by recognizing that, given convexity of the social planner's problem, a necessary and sufficient condition for $s^{*}$ to be positive is that:

$$
a . p_{s}(0 \mid h) \cdot\left(c_{h}-d\right)-(1-a) \cdot p_{s}(0 \mid l) \cdot\left(d-c_{l}\right)
$$

$$
+\left[a \cdot y_{x}\left(x(0) \mid c_{h}\right) \cdot x_{s}(0)+(1-a) \cdot y_{x}\left(x(0) \mid c_{)}\right) \cdot x_{s}(0)\right]+\left[\lambda \cdot x(0)+x_{s}(0)\right]<0
$$

This inequality is more likely to be satisifed under the conditions stated. []

The left-hand side of the inequality in Equation [11] is simply ( $d S L / d s$ ) evaluated in the vicinity of $s=0$ be negative. Given convexity of the planner's problem its being negative will ensure that the interior minimum will lie at some positive $s$. It cannot be determined a priori, then, whether or not this condition will be satisfied and so whether the environmental group's activities 
should be subsidized or taxed. Notice that this is true even in those cases in which $m$ is significantly greater than zero - i.e. where the under-incentive effect arising from the public nature of the rewards to contest effort by the EG is pronounced. It is more likely that a subsidy should be applied - that $s^{*}$ will be positive - when introducing a subsidy (i.e. incrementally raising $s$ from a base of $s=0$ ) has a comparatively small (though we know it to be positive) impact on the frequency with which the firm will lose contests even though $c=c_{h}$ and/or when the social cost of such an error is comparatively small or, conversely, when introducing a subsidy has a comparatively large (we know it to be negative) impact on the probability that the firm wins the contest even though $c=\mathcal{C}_{I}$ and/or when the social cost of such an error is comparatively large.

All of these relate to terms on the upper line of the expression on the left-hand side in Equation [11] and hence to the impact of introducing a subsidy on the quality of the regulatory decisions made by the contest system. $s^{*}$ is also more likely to be positive when the aggregate expected contest effort expended by the two parties is not too sensitive to changes in $s$ in the vicinity of $s=0$ - i.e. when the lower line is comparatively small (though unambiguously positive).

Implicit differentiation of Equation [10] also yields the comparative static results of interest: $s^{*}$ is decreasing in $\lambda$ and increasing in $m$ whilst the comparative static impacts of changes in any of the other parameters are qualitatively ambiguous. That $d s^{*} / d m$ is positive reflects the conventional wisdom that the greater the extent to which the potential rewards to the efforts of the environmental group are 'public' the greater the underincentive for it to exert effort and hence the greater the need for policy encouragement. Despite this, however, $m>0$ is in itself neither necessary nor sufficient to justify subsidy (i.e. to ensure that $s^{*}>0$ ) contrary to Shavell (1982).

As we have argued regulatory decision-making, when executed by private contest, is subject to both type 1 and type 2 errors (false rejections and false acceptances respectively). If we adopt the convention that the null state is 'no regulation' (reflecting a deregulatory predeliction) or, more generally, an outcome favourable to the firm - then the equilibrium probability that the regulatory apparatus will make a type 1 error - will impose or enforce a regulation when it shouldn't - is simply $p(s: h)$. We can now define the 'power' of the regulatory regime to be ( 1 $p(s \mid h))$ in a way exactly analogous to the power of a hypothesis testing procedure in statistics: the power of a statistical test captures its ability to avoid false rejection of a null hypothesis, the 
power of a regulatory decision-making apparatus is its ability to avoid 'bad' (welfare-reducing) regulation. (See Griliches and Intriligator (1984: 262) for a review of the concept of statistical power). Two things should be noted: (i) The social planner in this context does not pursue increases in the power of the regulatory decision-making process per se - his objective is to minimise an expected social loss function as has already been specified. It is, nevertheless, a useful and interesting descriptive statistic. ${ }^{15}$ (ii) In referring to the power of the regulatory regime it is necessary to specify whether the null state is deregulatory (as above) or regulatory. Unless otherwise stated we will always assume the former reflecting, arguably, contemporary political taste.

The following is stated without formal proof:

Proposition [4]: The power of regulatory decision-making by private contest is decreasing in the rate at which the activities of the environmental group are subsidized, $s$. The power of regulatory decision-making in the socially optimal regime (i.e. when $s=s^{*}$ ) is increasing in the shadow cost of public funds, $\lambda$.

The first part follows from the fact that $p_{s}(s \mid h)$ positive - an increase in $s$ increases the probability that, in equilibrium, the EG wins the contest (Proposition [1]) - implying that ( $I$ $p(s \mid h))$ is decreasing in $s$. The second follows directly from the recognition that $s^{*}$ is decreasing in $\lambda$ (as is confirmed by differentiation of Equation [10]).

\section{Regulation when Contest Expenditures are Pure Transfers}

We have assumed until now that the contest expenditures by both sides in a representative contest constitute net real resource costs. However, it is plausible to suppose that in many contexts some or all of the outlays incurred by the contestees will not represent net real resource costs but will, rather, be pure 'transfers' of wealth from contestees to other private agents. These could include the payment of (legal or illegal) 'bribes' paid to regulators, politicians or others, or paying for advertising in contexts where the marginal cost to the carrier of the advertisements is zero or small (as will often be the case) - see Yaeger (1991). 
It is interesting to consider how $s$ might be adjusted to take this into account. For simplicity suppose, momentarily, that $x$ and $y$ are pure transfers (think of them as 'bribes' given to 'buy' the support of third-parties in the contest process). In that case $x$ and $y$ do not in themselves constitute a real resource burden and it is appropriate to rewrite the social loss function (Equation [9]) as:

[9.b] $S L=a \cdot p(s \mid h) \cdot\left(c_{h}-d\right)+(1-a) \cdot(1-p(s \mid l)) \cdot\left(d-c_{l}\right)+\lambda \cdot s \cdot x(s)$

such that the associated first-order condition becomes:

$[10, \mathrm{~b}]$ a.p $s_{s}\left(s^{\prime} \mid h\right) \cdot\left(c_{h}-d\right)-(1-a) \cdot p_{s}\left(s^{*} \mid l\right) \cdot\left(d-c_{p}\right)+\lambda \cdot\left[x\left(s^{*}\right)+s^{*} \cdot x_{s}\left(s^{n}\right)\right]=0$.

(In each case the value of pure transfers has been deleted - though $x$ is still socially costly insofar as some proportion of it is still paid from public funds, the shadow cost of which is still strictly positive). The following can now be established:

Proposition [5]: When $x$ and $y$ are pure transfers (i) $s^{*}$ is higher such that (ii) social optimality will require the implementation of a regulatory decision-making regime with less power than when $x$ and $y$ are real resource outlays.

Proof: Appendix [2].

That this should be so is intuitive. When $x$ and $y$ are transfers the overall transactions cost burden of increasing $s$ is lower than in the earlier case and so optimality will require that it be raised nearer to the level at which the quality of regulatory decisions made is maximized - though it will still be below - where that level itself is the same as it was in the earlier case. Thus (i) $s^{*}$ is higher in the transfer case, and (ii) follows directly from the fact that $p(s \mid h)$ is everywhere increasing in $s$ such that $(I-p(s h))$ - the power of the decision-making regime - is everywhere decreasing in the same. 


\section{CONCLUSIONS}

Naysnerski and Tietenberg (1992), Miller (1988) and others have identified a creeping transfer of responsibility for the implementation of environmental regulation towards the private sector in recent years. This privatization has shown itself in a number of guises but all, ultimately, mean that effective environmental requirements are determined as the outcomes of 'contests' (of one sort or another, in one forum or another) between private agents and agencies.

The problems of modelling such contests adequately are manifold. Here we have used the imperfectly discriminating (or 'lottery') auction of Hirshleifer (1989), adopting a conventional unitlogit winning function. Our framework also incorporates what many believe to be the key asymmetry of information which hinders regulatory decision-making in this context - that the firm has, in general, private information regarding the likely cost implications of alternative regulations.

The question addressed in this paper is the following: If the process of environmental regulation is to be 'privatized' in the way outlined, how far (if at all) should the state be willing to subsidize the activities of those environmental groups on whose shoulders much of the responsibility for defending the environment is anticipated to fall.

It was shown that by manipulating the rate of tax-cum-subsidy the regulator can tilt the playing field on which the contests are fought and so affect (probabilistically) their outcomes. The problem, established in Proposition [2], is that he cannot do it selectively - tilting the playing field such as to make the environmental group more likely to win when it is socially desirable that it should cannot be done without, at the same time, making it more likely that it will win when it is socially desirable that it shouldn't. (The asymmetry of information regarding compliance costs, the underlying second-bestness here, prevents subsidies from being targeted). It cannot be established, a priori, whether optimality will require that the activities of the environmental groups be subsidised or taxed - the sign and size of $s^{*}$ depends in a complex way upon the various parameters of the model - and it is straightforward to develop numerical examples which go each way. What can be said is that increasing $s$ necessarily increases the transactions costs burden of the regulatory decision-making process (even when the regulated firm is induced to reduce the ferocity with which it contests regulatory decisions), whilst its effect on the quality of regulatory 
decisions is ambiguous (this is true whether contest efforts constitute real resource costs or are merely transfers of wealth within the private sector). Optimality will always require that $s$ be set at a level below that which maximizes the quality of regulatory decision-making, and will be lower in the real resource than in the transfer case.

The ambiguity in the sign of $s^{*}$ is contrary to the conventional line of argument that the altruistic raison d'etre of environmental groups necessarily implies that they merit support from the public pocket, either through explicit subsidies or through preferential tax treatment (tax relief on donations, covenants and bequests) or other channels. The convention that Greenpeace, Friends of the Earth and the Royal Society for the Protection of Birds (in the UK) are automatically granted charitable status (which amounts to an implicit subsidy in the form of tax advantages equal to $25-30$ per cent of income) is called into question by the result. It is conceivable that some industries are over-regulated as a result of the efficacy of the environmental group or groups with which they are paired (the nuclear electricity industry in the USA may be an example), and that those groups could fruitfully be made to pay tax at a standard or even higher than standard rate.

Our analysis is, of course, far from perfect. The world has been presented in a highly stylized way and there are a number of ways in which the treatment could be improved or extended. Three useful sets of refinements might be:

1 Fuller specification of contest process: The key thing in the model - the contest process itself - has been black-boxed here. Whilst the winning function adopted here, for example, has sensible characteristics it was essentially selected for ease of manipulation rather than realism. It would be more satisfactory if the function could be given more explicit 'institutional foundations'. Furthermore the timing of moves, pattern of payoffs and allocation of information could be specified to reflect underlying institutional fundamentals in particular regulatory contexts (Klevorick et al (1984) have attempted this in the context of criminal legal wrangles).

2 Fuller specification of objective functions: The objective functions attributed to the sides in the contest may fail to reflect their respective motivations correctly. There are a variety of reasons why directors of firms may want, and be able, to pursue objectives other than maximizing profits (maximizing sales, corporate growth, discretionary spending, dividend 
payments or some combination there of). Bureaucratic imperatives may also mean that NGO s pursue objectives other than the maximization of (net) environmental improvement - the desire by the head of an NGO to empire build may be as great as that of the management of a firm. Furthermore, in some contexts the return to winning a contest may exceed that supposed here. When the medium for a particular contest is civil litigation, for example, if the environmental group wins a suit that it brings it can reasonably expect to gain punitive damages and/or reimbursement of its legal expenses and these may be considerable ${ }^{16}$ Conversely, following civil law losses directors of companies found in breach of environmental statutes may subsequently face criminal punishment as individuals - a fact that can reasonably be expected to influence their approach to the civil suit. ${ }^{17}$

Under repetition (i.e. where regulation evolves through time by means of a sequence of regulatory disputes) how each party contests one particular case is also likely to be influenced by dynamics. The firm, for example, might seek to establish a reputation for being a 'tough fighter' by apparent over-spending on contest effort. The activities of NGOs may be subject to 'learningby-doing' with the productivity of the 'lobbying dollar' increasing as a function of cumulative lobbying done. There is certainly anecdotal evidence that many environmental pressure groups have become leaner, more professional and better-connected as a result of the experience that their staff and associates have collected in lobbying regulators, presenting themselves to the media and arguing cases in front of courts and tribunals (see, for example, Boehmer-Christiansen (1990)).

3 Richer specification of allocation of information: Two ways in which the model could be extended to (perhaps) make the allocation and dissemination of information in the model more realistic are: (i) In some cases the EG may have private information regarding $d$ - the monetary value of the environmental damage that would be proscribed by a particular regulatory action such that the game would be more appropriately modelled as one of two-sided asymmetric information. (ii) Some part of contest expenditures may generate or disseminate information directly (as opposed to implicitly). Thus effort spent by the firm communicating with a regulatory tribunal may allow it to transmit (albeit noisily) its private information regarding $c$ to that tribunal directly - through careful presentation of evidence for example - rather than the tribunal only 
being able to infer something about $c$ by observing the size of the firm's contest 'bid'. For the purposes of analysis we have assumed that the firm's private information is 'set in stone' and that contest expenditures are only implicitly informative. This is an improvement on existing analyses (Baik and Shogren (1994), Khambhu (1991)) in which contest behaviour conveys no information at all, but remains less than fully adequate. The difficulties arising in 'netting out' the pure lobbying component of observed contest expenditures are manifold.

4 Other instruments: There are a variety of other instruments which the social planner might envisage using instead of, or in addition to, subsidy/tax exemptions for NGOs. These can sensibly be grouped according to whether (i) they work by changing the institutional characteristics of the contest forum (and hence the form of the winning function) or (ii) they influence the behaviour of one or other of the contestees taking the winning function as given. ${ }^{18}$

Ultimately, of course, it would be interesting to attempt some empirical investigation. Notwithstanding its shortcomings we believe that our analysis is both interesting in its own right and suggests an interesting direction for more research. The trend in Europe, the USA and elsewhere towards an increased role for environmental tribunals, preemptive and restorative civil litigation and other private contests (including conflict through direct action) has been marked. The need to understand how interested parties conduct themselves in regulatory contests is a vital prerequisite to assessing the normative implications of the trend and how that trend might best be managed.

O.I.E.S 


\section{Notes}

1 I am extremely grateful to Dennis Snower, Sandeep Kapur, David Begg, Ron Smith, David Blake, Ngo van Long, Robert Cairns, Catherine Liston, and seminar participants at Birkbeck, Royal Holloway and Bedford Colleges of the University of London for heipful comments on earlier drafts of this paper. Errors are mine.

2 See, for example, Kalt and Zupan (1984). Boehmer-Christiannsen (1990) gives an interesting institutional account with particular reference to environmental policy.

3 More generally if both the costs and benefits are common knowledge then if a contest forum - such as a court - does exist it is difficult to understand the basis for its discretion since the 'correct' answer to the regulatory decision would also be apparent to all. It is the asymmetry of information in our model which can be seen as justifying both the existence of contest fora and the assumption that the decisions of those fora can go either way.

4 The word 'public' is used in the strict economic sense here to refer to that share of any environmental improvement which is external to the EG's objective function. This is not to say that the EG's motive for 'caring' about the other part is not altruism or sense of public-spiritedness.

5 Notice that the authors of the paper most similar to ours - Baik and Shogen (1994) implicitly restrict their attention to the case in which $c_{h}=d=c_{l}$. This is, as we have argued, a somewhat puzzling focus since it abstracts from what is the heart of the regulatory problem - the need to trade off (often uncertain) costs and benefits.

$6 \mathrm{~A}$ good example is when bids for public service contracts - such as provision of waste collection in a town - vary in a number of characteristics (various aspects of 'quality' as well as price) and the weights on the respective elements are stochastic and/or not known to the bidders.

7 'Bribes' must be of the non-contingent sort (i.e. paid up front rather than being contingent on a successful result) and may be of the legal or illegal variety according to context. The word is not necessarily used in a bad sense.

8 The assumption that the EG moves first may not be universally appropriate, though we believe it to be the best one to make in the great majority of contest contexts. There may be some contest arenas in which it would be better to model the conflict as a contemporaneous move game (in which case the appropriate solution concept would be Bayesian-Nash given the prevailing 
allocation of information) or as a war of attrition. In addition there may sometimes be scope for bargained solutions between the two parties (see Yaeger (1991)).

9 We assume that the firm's response is rational (profit maximizing) in this sense. Dimento (1986) identifies other factors which affect the firm's choice of contest effort and finds anecdotal evidence that personalities matter: 'Individual idiosyncracies of top managment can lead to a company's 'digging in' and fighting particular pieces of environmental law - the preference of top managers are an important factor in responsive behaviour in this context' (Dimento (1986: 84)).

10 Note that neither reaction function is defined at the origin.

11 The exception to this is when $x>c_{h}$ in which case $y=0$ (the firm cedes) in both cases.

12 Such a case could loosely be referred to as a 'separating' solution.

13 That $\lambda$ (the shadow cost of public funds) is strictly positive is an assumption routinely made in these contexts. It is one of the eight 'fundamental assumptions' retained by Laffont and Tirole (1993) throughout the analysis in their definitive handbook $A$ Theory of Incentives in Procurement in Regulation (Laffont and Tirole (1993: 38)). It reflects the fact that money raised by the government is raised through distortionary taxes. Its value is derived analytically by Laffont and Tirole (1993: 24). Estimated values of $\lambda$ for the USA range from 0.3 and 0.5 (Hausman and Poterba (1987)). They will be larger for countries with less developed tax collection regimes.

14 The 'quality' of regulatory decision-making will be taken to be measured by (minus) the expression $\left[a \cdot p(s \mid h) .\left(c_{h}-d\right)+(1-a) .(1-p(s \mid l)) .\left(d-c_{l}\right)\right]-$ the expected social burden of 'wrong' decisions vis-a-vis first-best or full-information decision-making.

15 The same can be said in econometrics. No one designs hypothesis tests to maximize power - power can trivially be maximized by setting acceptance criteria arbitarily low. It remains, nonetheless, a frequently used descriptive measure (see Griliches and Intriligator (1984)).

16 I am indebted to a referee for highlighting the important role of punitive damages in many civil environmental damage cases, particularly in the USA where the punitive component of damages may dwarf the compensatory component (American courts will routinely award at least triple damages). We have not built them into this model explicitly, however, because our analysis has, we hope, more general interpretation. It is intended to cover a variety of contest fora (not just, or even principally, civil law courts). Even in the context of civil law contests the 
analysis will cover proactive as well as compensatory claims (i.e. ex ante action by NGOs to prevent damage from being done in the first place (e.g. by contesting planning licences, claiming construction injunctions)) where punitive damages are never awarded. Baik and Shogren (1994), on the related subject of legal fees, compare the incentive implications of different legal cost sharing rules (the British system (loser pays) vs American system (each pays his own)).

17 Between 1982 and 1988, for example, the USEPA charged 393 company employees with criminal action leading to environmental damage. Of these 309 were convicted and punishment typically comprised 6-12 months imprisonment and 6-12 months probation (Russell (1990: 267)). See Dimento (1986) for a most insightful treatment of the criminalization of breaches of environmental law in the USA.

18 A third way in which the planner might intervene is to contest decisions himself (i.e. take the contest process as given and act as a player within it). In the context of the EC Green Paper EC93(47) - concerned with the redesign of environmental liability rules - there was considerable discussion regarding the standing of governmental or quasi-governmental organizations (publicly funded environmental watchdogs) vs NGOs in contexts where both can legitimately bring suit against a single would-be polluter. 
Appendix [1]: $x^{*}(s)$ is explicitly defined by Equation [8]. Differentiating with respect to $s$ yields:

[A.1.1] $\frac{d x}{d s}=\frac{1}{(1-s)} \cdot\left(\frac{a}{\sqrt{c_{H}}}+\frac{(1-a)}{\sqrt{c_{L}}}\right)^{3} \cdot\left(\frac{d .(1-m)}{2 .(1-s)}\right)^{3}$

which is positive. Changes in $s$ have no direct effect on $y$ so

$[\mathrm{A} .1 .2] \frac{d y^{2}}{d s}=y_{x}\left(x^{\cdot}(s) \mid c_{i}\right) \cdot \frac{d x}{d s}$

Since $(d x * / d s)$ is everywhere positive, $(d y * / d s)$ takes the sign of the slope of the firm's reaction function which is positive when and only when $y>x$ (i.e. when and only when the firm is favourite to win the contest). It can be seen from Equation [6] that the EG's equilibrium probability of winning $-p\left(x, y\left(x, c_{j}\right)\right)$ - is everywhere increasing in $x$. Overall, then, $p\left(x^{*}(s), y\left(x^{*}(s) \mid c_{j}\right)\right)$ is everywhere increasing in $s$.

Appendix [2]: The first thing to recognise is that whether $x$ and $y$ are real resource costs or transfers has no implications for the behaviour of the EG or firm. Subtracting Equation [10 b] from Equation [10] implies that (in obvious notation)

$\left[\right.$ A.2.1] $\frac{d S L_{\text {real }}}{d s}-\frac{d S L_{\text {trasfor }}}{d s}=x_{s^{\prime}}\left[1+a \cdot y_{x}(s \mid h)+(1-a) \cdot y_{x}(s \mid l)\right]$

It can be inferred from routine manipulation of Equations [8] and [3] that this expression is positive. Letting $s_{\text {real }}$ and $s_{\text {transfer }}$ be the values of $s$ which minimize $S L_{r e a l}$ and $S L_{\text {tronsfer }}$ respectively, application of the envelope theorem implies that

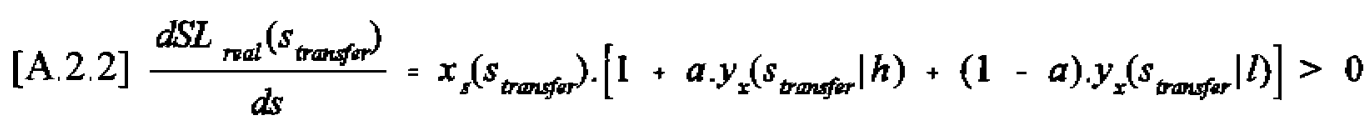

Given convexity of the social planner's problem this implies that $s_{\text {transfer }}>s_{\text {real }}$, as stated in part (i) of Proposition [5]. Part (ii) of Proposition [5] follows directly from the fact that the power of the decision-making procedure is decreasing in $s$ (see Proposition [4]).

O.I.E.S. 


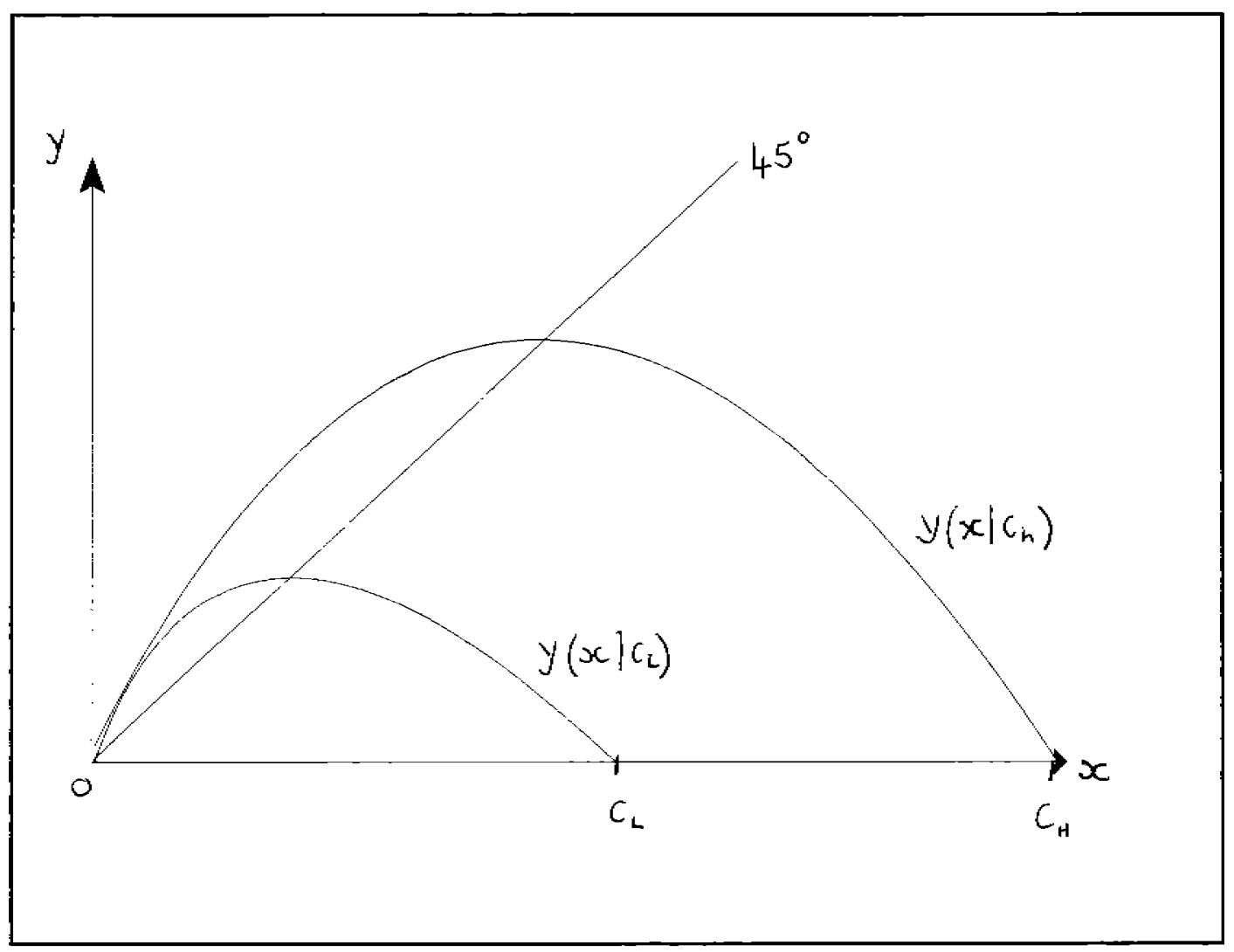

Figure [1]: The firm's $c_{i}$-contingent reaction functions 


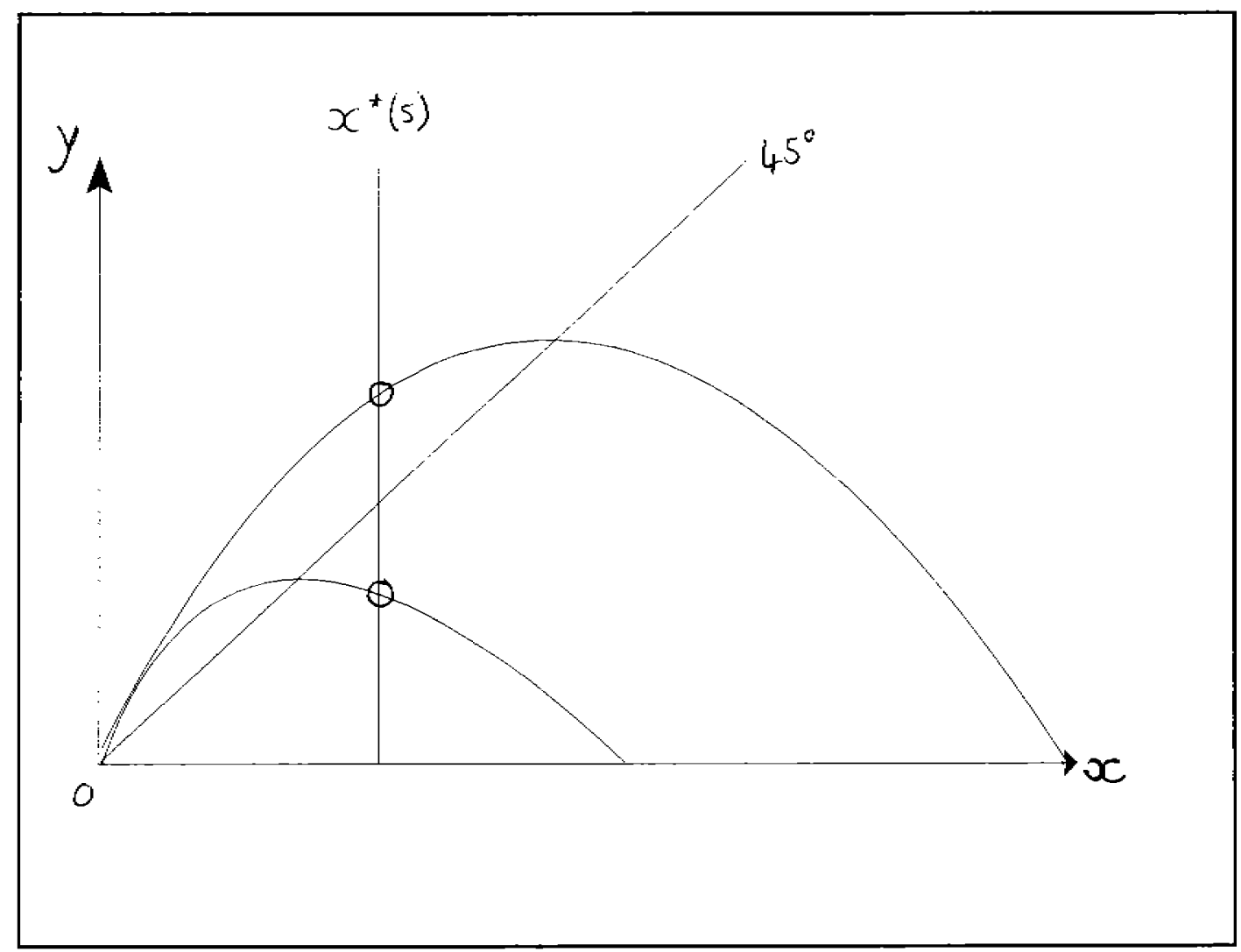

Figure [2]: Pair of $c_{i}$-contingent Stackelberg equilibria 


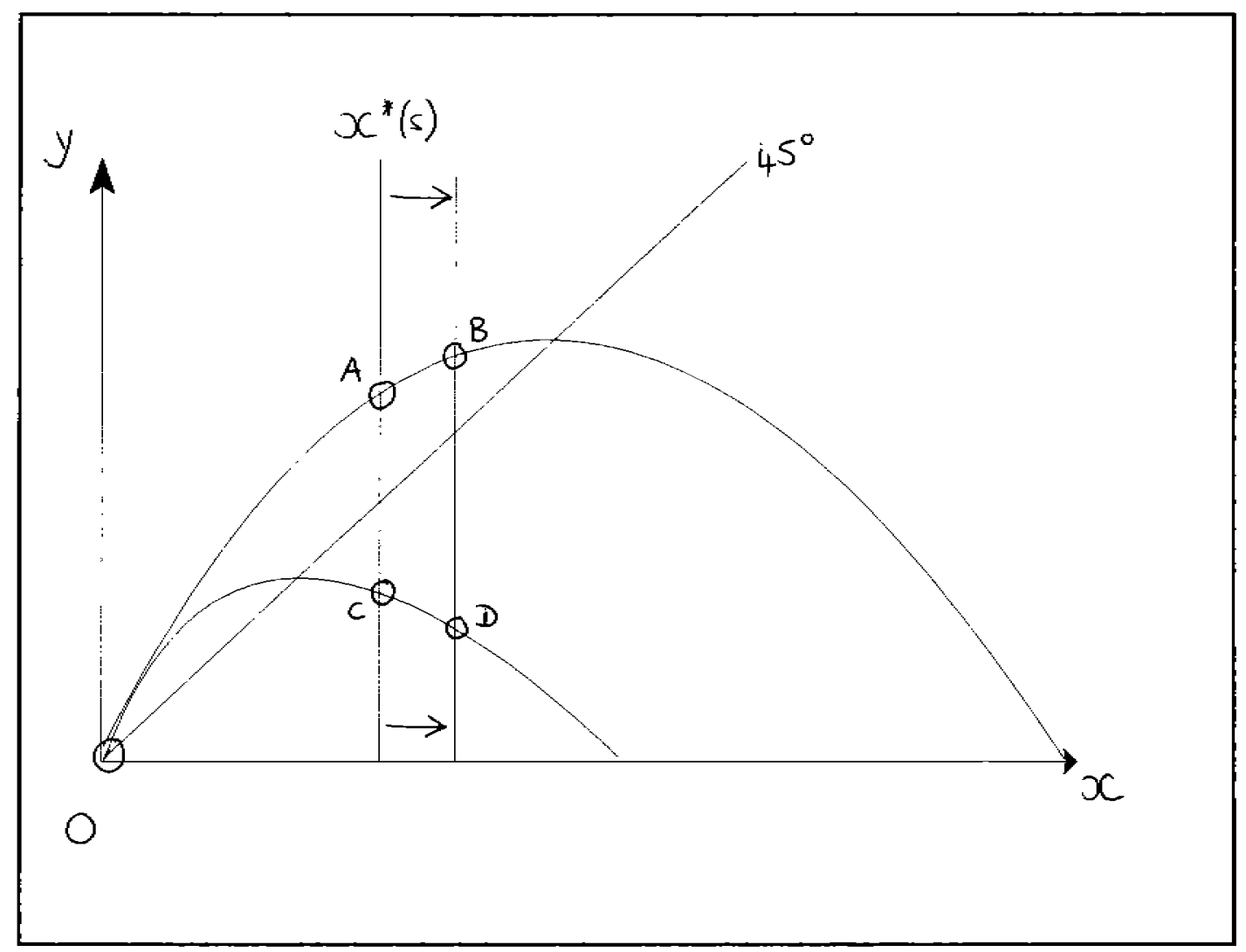

Figure [3]: Impact of increase in $s$ on Stackelberg equilibria 


\section{BIBLIOGRAPHY}

Baik, K. and J. F. Shogren (1994), "Reimbursements for Citizen's Suits", Journal of Environmental Economics and Management (21), 1-20.

Baron, D. and R. Myerson (1982), "Regulating a Monopolist with Unknown Costs" Econometrica (51), 326-46.

Boehmer-Christiansen, S. A. (1990), "Energy Policy and Public Opinion: Manipulation of Environmental Threats by Vested Interests in the UK and West Germany", Energy Policy (November), 828-37.

Buchanan, J., R. Tollinson and G. Tullock (1990), Toward a Theory of the Rent-Seeking Society, Texas A\&M University Press, College Station.

Cairns, R. D. (1992), "Dynamic Rent-Seeking", Journal of Public Economics (39), 315-26.

Dimento, J. (1986), They Treated Me Like A Criminal, University of Pittsburgh Press.

Dixit, A. (1987), "Strategic Behaviour in Contests" American Economic Review (77), 89198.

Gritiches, Z. and M. Intriligator (1984), "Handbook of Econometrics" (Volume 2), Elsevier/North Holland, Amsterdam.

Hausman, J. and J. Poterba (1987), "Household Behaviour and Tax Reform", Journal of Economic Perspectives (1), 101-19.

Hawkins, K. and J. M. Thomas (eds) (1988), Making Regulatory Policy, University of Pittsburgh Press.

Heyes, A. G. (1994), "The Economics of Strict and Fault-based Environmental Liability" European Environmental Law Review 3(10), 293-300.

Heyes, A. G. (1995), "Allocation of Environmental Liability and the Equilibrium Cost of Capital" mimeo Birkbeck College, University of London (forthcoming in Economica).

Hillman, A. and J. Riley (1989), "Politically Contestable Rents and Transfers", Economics and Politics (1), 17-39.

Hirshleifer, J. (1988), "The Analytics of Continuing Conflict", Synthese (76), 201-33.

Hirshleifer, J. (1989), "Conflcit and Rent-Seeking Success Functions: Relative versus Difference Models of Relative Success" Public Choice (63), 101-12.

Kalt, J. P. and M. A. Zupan (1984), "Capture and Ideology in the Economic Theory of Politics", American Economic Review (74), 279-300. 
Kambhu, J. (1991), "Regulatory Standards, Non-compliance and Enforcement" Journal of Regulatory Economics (1), 103-14.

Klevorick, A., M. Rothschild and C. Winship (1984), "Information Processing and Jury Decisionmaking", Joumal of Public Economics (23), 245-78.

Laffont, J. J. and J. Tirole (1993), A Theory of Incentives in Procurement and Regulation, MIT Press, Cambridge, MA.

Law Reform Commission of Canada (1988), "Pollution Control in Canada: The Regulatory Approach", Administrative Law Series Study Paper, Ottawa.

Margavio, A., S. Laska and J. Mason (1993), "Captives of Conflict", Society and Natural Resources (6), 273-90.

Miller, J. (1988), "Private Enforcement of Federal Pollution Control Laws", Environmental Law Reponter (14), 10063-10320.

Naysnerski, W. and T. Tietenberg (1992), "Private Enforcement of Federal Environmental Law", Land Economics (68), 28-48.

Probst, K. and P. R. Portney (1992), Assigning Liability for Superfund Cleanups, Resources for the Future, Washington DC.

Probst, K., D. Fullerton, R. E. Litan and P. R. Portney (1995), "Footing the Bill for the Superfund Cleanups" Brookings Institution and Resources for the Future (joint publication), Washington DC.

Russell, C. (1990), "Monitoring and Enforcement", in Paul R. Portney (ed.) Public Policies for Environmental Protection, Resources for the Future, Washington DC.

Shavell, S. (1982), "The Social vs Private Incentive to Bring Suit in a Costly Legal System" Joumal of Legal Studies (11), 333-39.

Wilkinson, P. (1993), "Environmental Litigation and Pollution Control", European Environmental Law Review, 28-34.

Xepedeas, A. P. (1991), "Environmental Policy Under Imperfect Information: Incentives and Moral Hazard", Joumal of Environmental Economics and Management (20), 113-26.

Yaeger, P. E. (1991), The Limits of the Law: Public Regulation of Private Pollution, Cambridge University Press, New York NY. 
OXFORD INSTITUTE FOR ENERGY STUDIES

57 WOODSTOCK ROAD, OXFORD OX2 6FA ENGLAND TELEPHONE (01865) 311377

FAX (01865) 310527

E-mail: publications@oxfordenergy.org

http://www.oxfordenergy.org 